\title{
AN IMPROVED POWER CONTROLLER FOR A SINGLE PHASE GRID CONNECTED INVERTER WITH ROOT LOCUS ANALYSIS
}

\author{
Élcio Precioso de Paiva**, João Batista Vieira Jr.*, Luís Carlos de Freitas*, \\ Valdeir José Farias*, Ernane Antônio Alves Coelho* \\ **Coordenação Área Indústria, Escola Técnica Federal de Palmas \\ AE 310 Sul Av. NS 10 esq, c/ Av. LO-5A, Centro 77021-090 Palmas, TO \\ *Núcleo de Pesquisa em Eletrônica de Potência, Faculdade de Engenharia Elétrica, Universidade Federal de Uberlândia \\ Av. João Naves de Ávila, 2121 - Campus Santa Mônica, 38400 -902 Uberlândia, MG
}

elciopaiva@etfto.gov.br, batista@ufu.br, freitas@ufu.br, valdeir@ufu.br, ernane@ufu.br

\begin{abstract}
This paper presents an improved controller for a single-phase inverter connected to the grid, which is based on frequency and voltage droops. A new feedback loop is introduced to increase the system damping. The small signal analysis and root locus plots are presented in order to show the connections between the feedback loop gains and the behavior of the system. Simulation results corresponding to the numerical solution of the nonlinear system equations are presented to validate the small signal analysis. A description of a laboratory prototype and the respective experimental results are also presented to confirm the theoretical analysis.
\end{abstract}

Keywords - Sinusoidal PWM Inverters, Parallel Connection, Frequency and Voltage Droops, Phase Feedback, Small Signal Analysis.

\section{INTRODUCTION}

In the last years there has been an increasing interest in parallel connection of inverters for application in distributed uninterruptible power supply (UPS) systems or renewable energy grid integration. Several parallel control techniques have been proposed to connect inverters in an island grid or to connect an inverter to an infinite bus [1-9].

The frequency and voltage droop control method is the preferred technique because it is able to avoid control interconnections and has no master-slave relationship [3, 6, 9]. This method is derived from electric power system control and its dynamic characteristics can be obtained by small signal analysis using linear techniques $[5,6,10]$.

Stability study of single-phase inverter connected to stiff AC system is presented in [5]. It can be seen that to improve the dynamic response of the paralleled system it is necessary to increase the droop coefficients, but this reduces the system damping and can make system unstable.

In order to improve the dynamic response of the system and maintain a suitable damping, an extra loop feedback is

Manuscript received on 03/08/2007. Revised on 24/10/2007 and 26/10/2008. Accepted by recommendation of the Editor Fernando L. M. Antunes. proposed. This loop feeds the active power variation back into the phase of the inverter output voltage. A new small signal model is presented including the proposed loop and experimental results showing the effect of this loop in the system behavior.

\section{CONTROL SCHEME}

The controller proposed to connect the single-phase inverter to stiff AC system is shown in Figure 1. The inverter is composed of the H-bridge (four IGBT and four freewheeling diodes) and a low-pass filter formed by Rf, Lf and Cf. The inverter is connected to the grid through a transmission line.

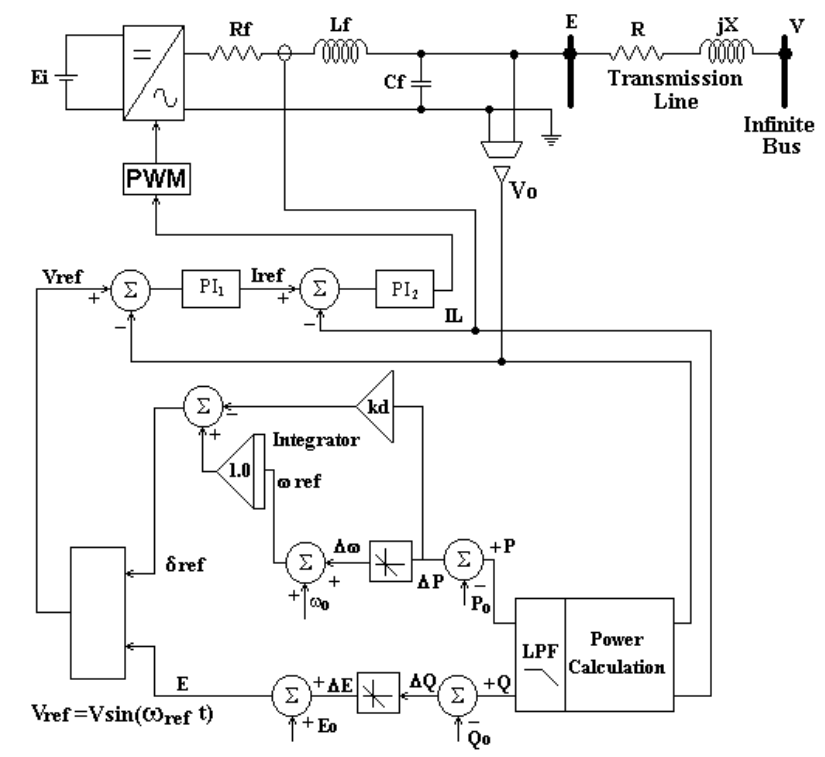

Fig. 1. Single-phase inverter connected to stiff AC system with the improved controller

The controller consists of an inner current loop, a voltage loop, both using PI compensators, and an outer power sharing loop, which has the power calculation block, the conventional frequency and voltage droops and the proposed loop. In order to increase the system damping a new feedback loop is introduced, that is, an active power deviation from the equilibrium point not only implies a frequency displacement, resulting in an integral action on the 
phase, but also a direct displacement of the phase of the inverter.

\section{SMALL SIGNAL ANALYSIS}

Inverter output frequency $\omega$ and inverter output voltage $\mathrm{E}$ are controlled by the droop characteristics defined by (1) and (2), respectively, which are represented in Figure 2 [5-7].

$$
\begin{aligned}
& \omega=\omega_{0}-K_{p} \cdot(P-P o) \\
& E=E_{0}-K_{v} \cdot(Q-Q o)
\end{aligned}
$$
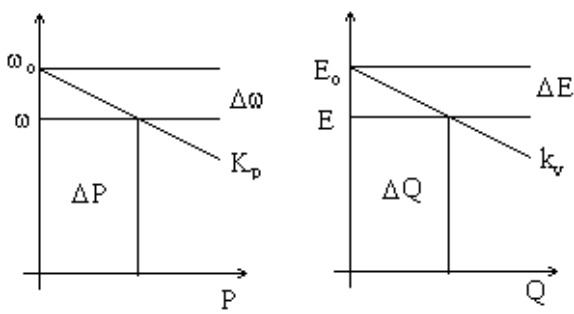

Fig. 2. Frequency and voltage droops

The active power and the reactive power transferred from the inverter to the stiff AC system are given by (3) and (4), respectively $[5,10]$. In this case, these expressions include the power losses and the reactive power through the inductive reactance associated with the transmission line.

$$
\begin{aligned}
& P=\frac{1}{R^{2}+X^{2}}\left(R E^{2}-R E V \cos \delta+X E V \sin \delta\right) \\
& Q=\frac{1}{R^{2}+X^{2}}\left(X E^{2}-X E V \cos \delta-R E V \sin \delta\right)
\end{aligned}
$$

Considering small disturbances around the stable equilibrium point defined by $\left(\delta_{\mathrm{e}}, \mathrm{E}_{\mathrm{e}}, \mathrm{V}_{\mathrm{e}}\right)$, the above equations can be linearized, then we have:

$$
\begin{aligned}
& \Delta \omega=\frac{\partial \omega}{\partial P} \Delta P \\
& \Delta E=\frac{\partial E}{\partial Q} \Delta Q \\
& \Delta P=\frac{\partial P}{\partial E} \cdot \Delta E+\frac{\partial P}{\partial \delta} \cdot \Delta \delta \\
& \Delta Q=\frac{\partial Q}{\partial E} \Delta E+\frac{\partial Q}{\partial \delta} \Delta \delta
\end{aligned}
$$

Where $\Delta$ denotes the small deviation of the variable from the equilibrium point. Substituting for $\mathrm{P}$ and Q given by (3) and (4) and calculating the partial derivatives, we obtain:

$$
\begin{aligned}
& \Delta \delta=-K_{D} \cdot \Delta P-\frac{K_{P .} \Delta P}{s} \\
& \Delta E=-K_{V} \cdot \Delta Q \\
& \Delta P=k_{p e} \Delta E+k_{p d} \Delta \delta
\end{aligned}
$$

$$
\Delta Q=k_{q e} \Delta E+k_{q d} \Delta \delta
$$

where:

$$
\begin{aligned}
& \mathrm{Kpe}=\frac{1}{\mathrm{R}^{2}+\mathrm{X}^{2}}\left(2 R E_{e}-R V_{e} \cos \delta_{e}+X V_{e} \operatorname{sen} \delta_{e}\right) \\
& \mathrm{Kpd}=\frac{1}{\mathrm{R}^{2}+\mathrm{X}^{2}}\left(R E_{e} V_{e} \operatorname{sen} \delta_{e}+X E_{e} V_{e} \cos \delta_{e}\right) \\
& \mathrm{Kqe}=\frac{1}{\mathrm{R}^{2}+\mathrm{X}^{2}}\left(2 X E_{e}-X V_{e} \cos \delta_{e}-R V_{e} \operatorname{sen} \delta_{e}\right) \\
& \mathrm{Kqd}=\frac{1}{\mathrm{R}^{2}+\mathrm{X}^{2}}\left(X E_{e} V_{e} \operatorname{sen} \delta_{e}-R E_{e} V_{e} \cos \delta_{e}\right)
\end{aligned}
$$

The active and reactive output powers obtained by the measuring block can be given by (17) and (18), where $\omega_{f}$ is the cut-off frequency of the measuring filter.

It is important to take into account that the measuring filter presents a bandwidth much smaller than the inner controllers of the inverter and the system performance will have a hard influence of this fact. In addition, the bandwidth of the inner controllers can be increased using several techniques [11]. Then, we consider the inverter as an ideal voltage source with controllable amplitude and frequency.

$$
\begin{aligned}
& \Delta \mathrm{P}_{\text {avg }}(s)=\frac{\omega_{f}}{s+\omega_{f}} \Delta \mathrm{P}(s) \\
& \Delta Q_{\text {avg }}(s)=\frac{\omega_{f}}{s+\omega_{f}} \Delta \mathrm{P}(s)
\end{aligned}
$$

Therefore, it follows from above equations:

$$
\begin{aligned}
& \Delta \delta=-K_{D} \cdot \frac{\omega_{f}}{s+\omega_{f}} \cdot \Delta P-\frac{K_{P}}{s} \cdot \frac{\omega_{f}}{\left(s+\omega_{f}\right)} \cdot \Delta P \\
& \Delta E=-K_{V} \cdot\left[K_{q e} \cdot \Delta E+K_{q d} \cdot \Delta \delta\right] \frac{\omega_{f}}{s+\omega_{f}} \\
& \Delta E=-\frac{K_{V} \cdot K_{q d} \cdot \omega_{f} \cdot \Delta \delta}{s+\omega_{f} \cdot\left(1+K_{V} \cdot K_{q e}\right)}
\end{aligned}
$$

Substituting (9) and (21) in (11) and expanding it, results:

$$
\Delta P=\left[\frac{-K_{V} \cdot K_{p e} \cdot K_{q d} \cdot \omega_{f}+K_{p d} \cdot\left(s+\omega_{f} \cdot\left(1+K_{V} \cdot K_{q e}\right)\right)}{s+\omega_{f} \cdot\left(1+K_{V} \cdot K_{q e}\right)}\right] \cdot \Delta \delta
$$

Since phase $\delta$ is the frequency $\omega$ time integral, thus: 


$$
\Delta \omega(s)=s . \Delta \delta(s)
$$

Substituting (23) in (22) and expanding it, results:

$$
s^{3} \Delta \delta(s)+a s^{2} \Delta \delta(s)+b s \Delta \delta(s)+c \Delta \delta(s)=0
$$

where:

$$
\begin{aligned}
& a=\left(\omega_{f \cdot}\left(2+K_{V \cdot} \cdot K_{q e}\right)+K_{D} \cdot \omega_{f \cdot} K_{p d}\right) \\
& b=\left(\omega_{f}^{2} \cdot\left(1+K_{V} \cdot K_{q e}\right)+K_{P} \cdot \omega_{f \cdot} K_{p d}-K_{D} \cdot K_{V} \cdot K_{p e} \cdot K_{q d} \cdot \omega_{f}^{2}+\right. \\
& \left.+K_{D} \cdot \omega_{f}^{2} \cdot K_{p d} \cdot\left(1+K_{V} \cdot K_{q e}\right)\right) \\
& c=K_{P} \cdot \omega_{f}^{2} \cdot\left(K_{p d \cdot}\left(1+K_{V} \cdot K_{q e}\right)-K_{V} \cdot K_{p e} \cdot K_{q d}\right)
\end{aligned}
$$

Then, the system response can be analyzed by characteristic equation (28).

$$
\lambda^{3}+a \lambda^{2}+b \lambda+c=0
$$

\section{SIMULATION RESULTS}

Some simulations were made in order to validate the small signal model. Two examples for different gain $K_{D}$ are presented, which emphasize the influence of the feedback from $\Delta P$ to $\Delta \delta$.

\section{A. Example I}

Taking the system showed in Figure 1 with the parameters presented in Table 1, tunning offset of frequency droop and tuning the offset of voltage droop in way that inverter provides the apparent power specified in Table 1, we can obtain the behavior of angle $\Delta \delta$ of the system. Using $K_{D}=0$, we have the conventional control showed in [5], that is, there is no additional damping.

TABLE I.

System Parameters and Equilibrium Point

\begin{tabular}{lcc}
\hline \multicolumn{1}{c}{ Variable } & Value & Unit \\
\hline Line impedance & $0.5+j 3.44$ & $\Omega$ \\
\hline Cut-off freq. of measuring filter $(\omega \mathrm{f})$ & 7.54 & $\mathrm{rd} / \mathrm{s}$ \\
\hline Frequency droop coefficient $\omega x \mathrm{~K}(\mathrm{Kp})$ & 0.01 & $\mathrm{rd} / \mathrm{s} / \mathrm{W}$ \\
\hline Voltage droop coefficient ExQ $(\mathrm{Kv})$ & 0.01 & $\mathrm{~V} / \mathrm{VAR}$ \\
\hline Feedback loop gain of $\Delta \delta / \Delta \mathrm{P}\left(\mathrm{K}_{\mathrm{D}}\right)$ & 0 & $\mathrm{rd} / \mathrm{W}$ \\
\hline Apparent power in stiff AC system & $500+\mathrm{j} 0$ & $\mathrm{VA}$ \\
\hline Inverter output apparent power & $510.8+\mathrm{j} 74.8$ & $\mathrm{VA}$ \\
\hline Stiff AC system voltage $(\mathrm{V})$ & 107.2 & $\mathrm{~V}(\mathrm{rms})$ \\
\hline Inverter output voltage $(\mathrm{E})$ & 110.7 & $\mathrm{~V}(\mathrm{rms})$ \\
\hline Stiff AC system frequency $(\omega)$ & 377 & $\mathrm{rd} / \mathrm{s}$ \\
\hline Output filter Inductor $L_{f}$ & 796 & $\mu \mathrm{H}$ \\
\hline Output filter Capacitor $C_{f}$ & 60 & $\mu \mathrm{F}$ \\
\hline Inverter Switching Frequency $\mathrm{f}_{\mathrm{S}}$ & 18 & $\mathrm{kHz}$ \\
\hline DC link Capacitor & 470 & $\mu \mathrm{F}$ \\
\hline Inverter-stiff AC system lead angle & 0.1454 & $\mathrm{rd}$ \\
$(\Delta \delta)$ & & \\
\hline
\end{tabular}

Solving the characteristic equation (28), we have the following eigenvalues:

$$
\begin{aligned}
& \lambda_{1}=-3.7703+j 15.5986 \\
& \lambda_{2}=-3.7703-j 15.5986 \\
& \lambda_{3}=-9.9677
\end{aligned}
$$

Considering that initial active and reactive powers are zero, we can obtain the behavior of the system by (24). It is important to keep in mind that (24) provides the deviation from the equilibrium point, and that the behavior of the angle $\delta$ is determined by the following equation:

$$
\delta=\delta_{\text {eq.point }}+\Delta \delta
$$

The system presents two complex conjugated poles and one negative real pole, therefore it presents an oscillatory response. Figure 3 presents the phase response of singlephase inverter connected to stiff AC system obtained from the model described by (24) and simulation in PSpice. The active power and reactive power are presented in Figure 4. It can be noticed that reactive power is faster than active power, which presents oscillatory response.

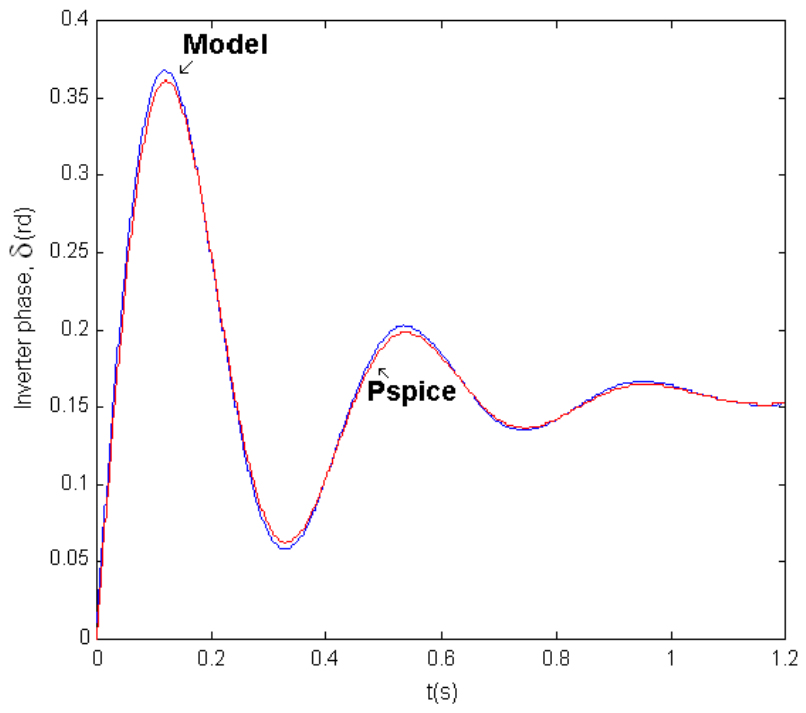

Fig. 3. Phase response of the inverter

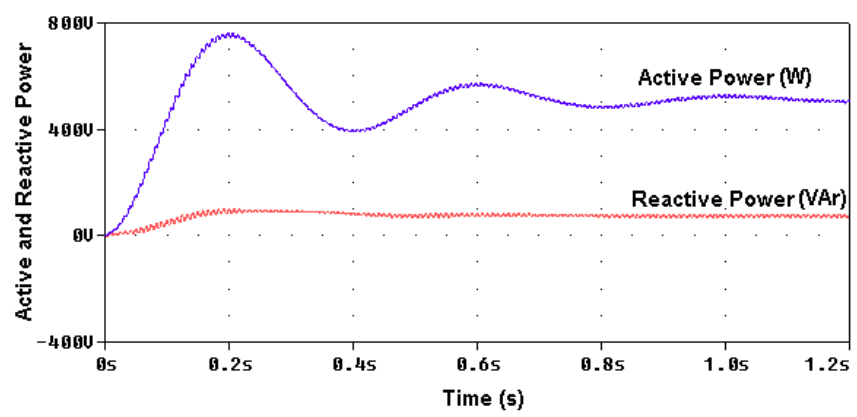

Fig. 4. Active and reactive powers 
Figure 5 presents the output voltage and current supplied by inverter. The current was multiplied by a factor of 10 to make it more visible.

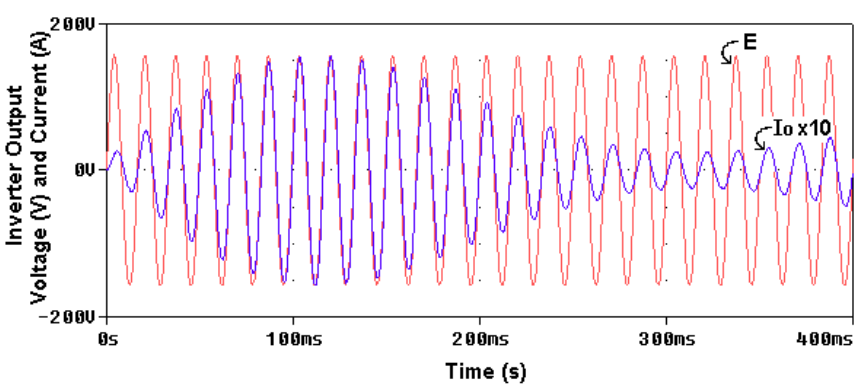

Fig. 5. Output voltage and output current

\section{B. Example II}

The same parameters from the Example I are used in Example II, except that now $\mathrm{K}_{\mathrm{D}}=1 \mathrm{e}-3$, which implies that the new feedback loop is working.

In this case, solving (28), the following eigenvalues are obtained:

$$
\begin{aligned}
& \lambda_{1}=-21.0733 \\
& \lambda_{2}=-12.2200 \\
& \lambda_{3}=-9.9683
\end{aligned}
$$

It can be noticed that poles have only negative real parts and no imaginary parts, so the system is overdamped. It can be inferred that the proposed loop can change the underdamped system (Example I) into a overdamped system (Example II).

Figure 6 shows the behavior of the angle $\delta$ obtained by the small signal model and the simulation in PSpice. The results are very close and we can resume that the system is well represented by the small signal model.

The active and reactive powers are shown in Figure 7, which characteristics can be classified as overdamped.

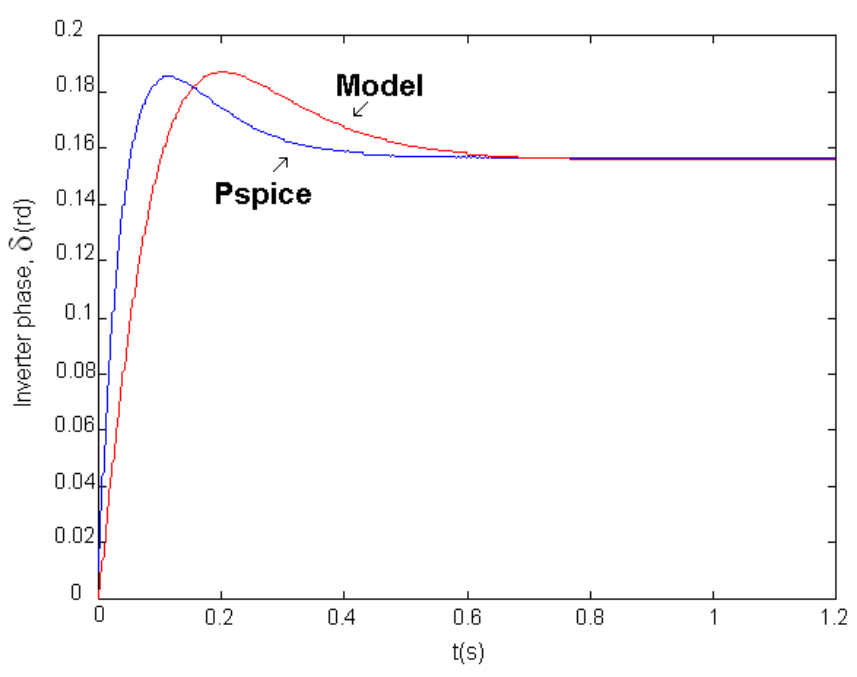

Fig. 6. Phase response of the inverter

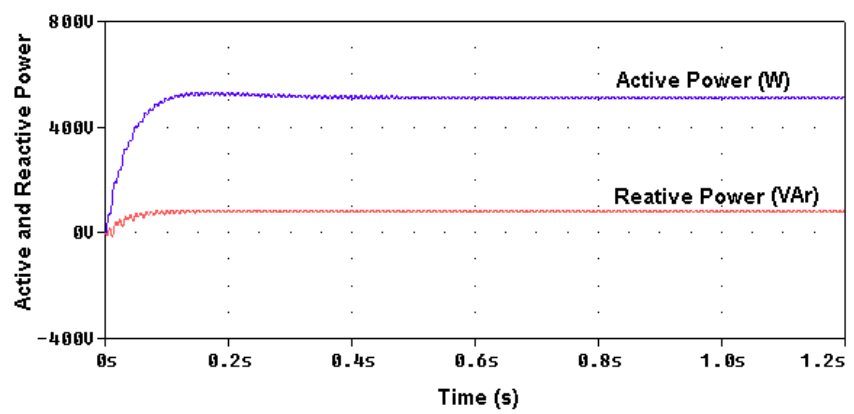

Fig. 7. Active and reactive powers

Figure 8 presents the output voltage and output current supplied by the inverter.

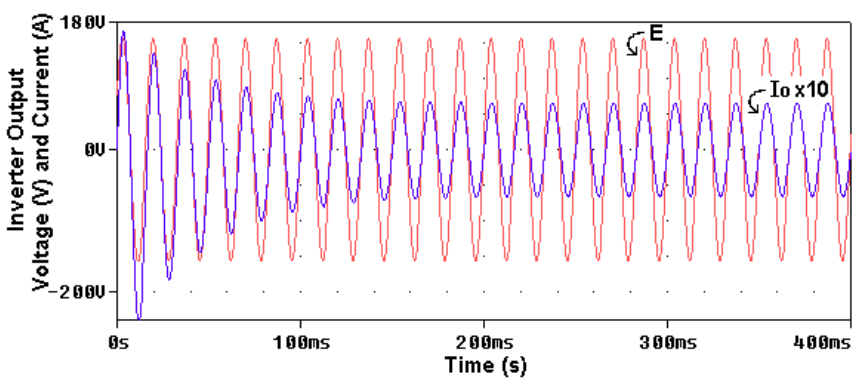

Fig. 8. Output voltage and output current

\section{DYNAMIC BEHAVIOR OF THE SYSTEM}

In order to understand the dynamic behavior of the system, a root locus plots is shown as a function of the parameter $K_{D}$.

Figure 9 shows the system root locus plots considering that the droop coefficients $K_{p}$ and $K_{v}$ are equal to $0.01 \mathrm{rd} / \mathrm{s} / \mathrm{W}$ and $0.01 \mathrm{~V} / \mathrm{VAr}$, respectively and $\mathrm{K}_{\mathrm{D}}$ varies from 0 to $1 \mathrm{e}-3$ $\mathrm{rd} / \mathrm{W}$. When $K_{D}=1 \mathrm{e}-3$, it can be seen that the system presents a damping greater than to $\mathrm{K}_{\mathrm{D}}=0$, assuming that the proposed model is valid.

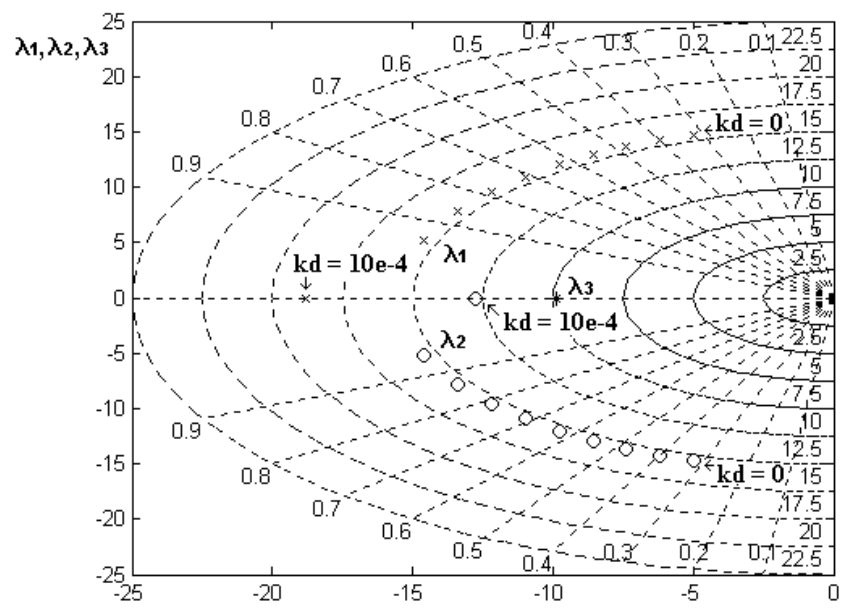

Fig. 9. Root locus plot for $K_{p}=K_{v}=0.01$ and $K_{D}$ variation from 0 to 0.001 


\section{DYNAMIC BEHAVIOR OF THE SYSTEM WITH LINE IMPEDANCE VARIATION}

Figure 10 shows system root loci obtained by varying the line inductance $\left(L_{\mathrm{t}}\right)$ from $0.1 \mathrm{mH}$ to $10 \mathrm{mH}$, with a step of 0.1 $\mathrm{mH}$. In both figures, $\mathrm{Kp}=\mathrm{Kv}=0.02$. In Figure 10 (a) $\mathrm{K}_{\mathrm{D}}=0$ and in Figure 10 (b) $K_{D}=1 e-3$. It can be observed in the first root locus that the system becomes unstable for line inductances smaller than $1.6 \mathrm{mH}$ approximately. When the proposed loop is working, the system becomes stable over the given range of inductance, as can be seen in Figure 10(b).

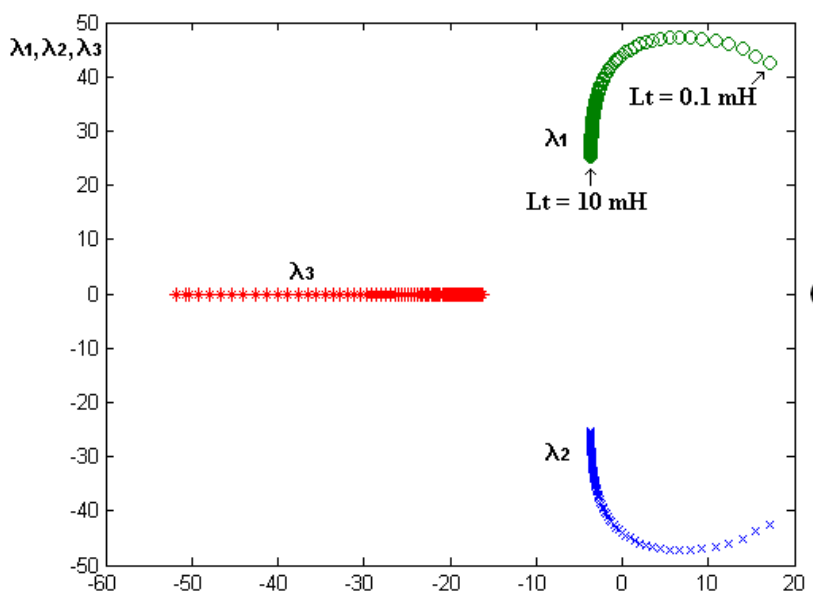

(a)

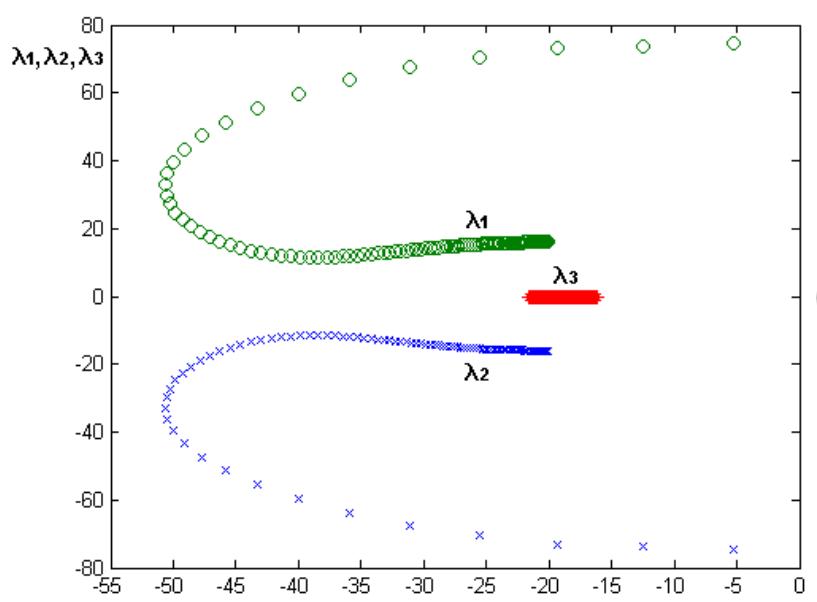

Fig. 10. Root locus plot for $L t$ variation from $0.1 \mathrm{mH}$ to $10 \mathrm{mH}$ $K p=K v=0.02$; (a) $K_{D}=0$; (b) $K_{D}=1 e-3$.

\section{EXPERIMENTAL RESULTS}

A laboratory prototype was assembled in order to validate the theoretical studies and its parameters are the same of the Table I. It consists of a single-phase PWM inverter connected to stiff AC system with an inner PI current control loop and an outer PI voltage control loop, as can be seen in Figure 11. First of all, the IGBT gate drivers of the inverter are disabled, and then the switch SW1 is closed. An AC voltage appears in the filter capacitor of the inverter due to the stiff AC system. The reference voltage of the inverter is synchronized with the capacitor voltage by a PLL (Phase Locked Loop) block, and then, at $0.1 \mathrm{~s}$ after the acquisition system starts saving data, the IGBT gate drivers are enabled and the switch SW2 is changed from state 1 to state 2 . Thus, the power flux controller starts working.

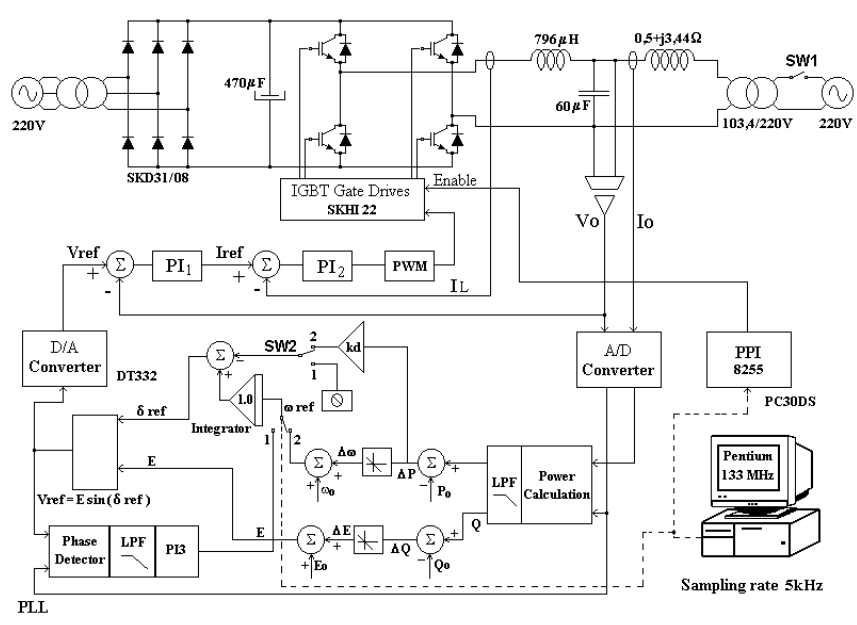

Fig. 11. Laboratory Prototype Scheme

\section{A. Analysis for $K_{D}=0$}

The experimental results with $K_{D}=0$ are showed in the figures listed below. In Figure 12, it can be noted that before the inverter being connected with the stiff AC system, the output current and the output voltage have significant distortion because of the harmonic pollution present in the utility system at the point of connection. When the inverter is enabled to work in parallel with the grid at instant $t=0.1 \mathrm{~s}$, the output voltage and the output current become significantly more sinusoidal.

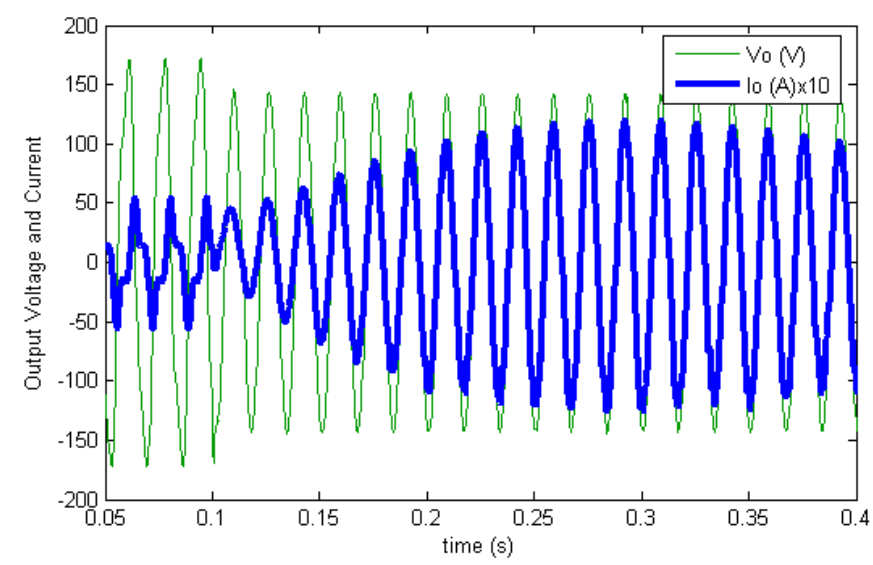

Fig. 12. Output voltage and output current.

$$
\mathrm{K}_{\mathrm{D}}=0
$$

Figure 13 shows active and reactive powers that the inverter provides to the stiff AC system with no feedback between $\Delta P$ and $\Delta \delta$, i.e., without the new control loop $\left(\mathrm{K}_{\mathrm{D}}=\right.$ $0)$. In this case, it can be seen that the active power has a quite oscillatory response. The filter capacitor of the inverter provides a reactive power for the utility system before the power controller is enabled to work, then, the reactive power curve didn't start from zero. 


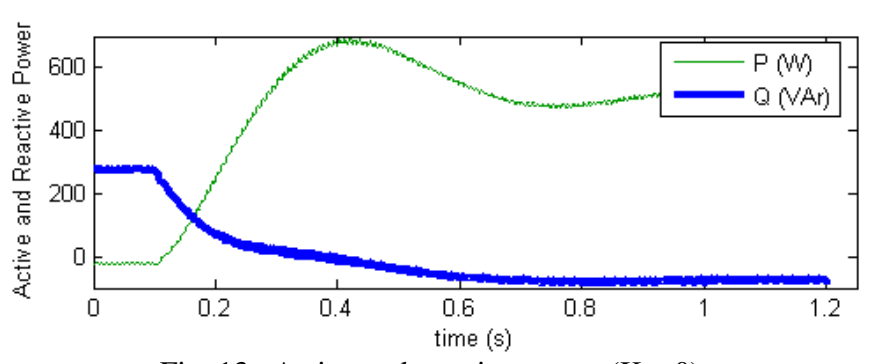

Fig. 13. Active and reactive power $\left(K_{D}=0\right)$

Figure 14 represents the inverter frequency during the transient of the connection to the utility system. It can be observed that the frequency has an oscillatory response, as it was expected from the theoretical analysis, since the frequency $\omega$ is the angle $\delta$ derivative in time.

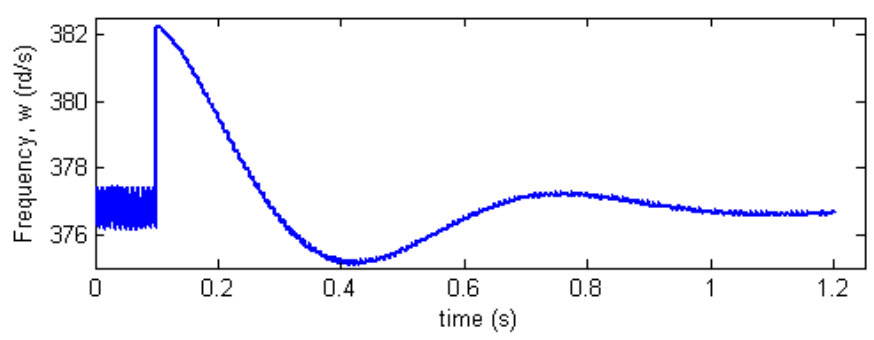

Fig. 14. Inverter frequency $\left(K_{D}=0\right)$

\section{B. Analysis for $K_{D}=0.001$}

The results achieved using $K_{D}=1 e-3$, i.e., with the feedback between $\Delta P$ and $\Delta \delta$ are presented in the following figures.

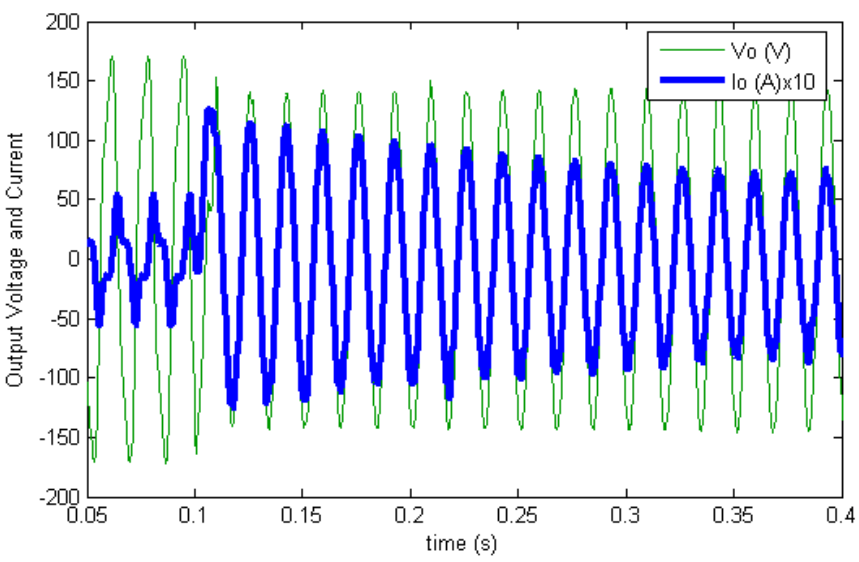

Fig. 15. Output voltage and output current $\left(K_{D}=1 e-3\right)$

Figure 15 shows the inverter output voltage and current and figure 16 shows active and reactive powers.

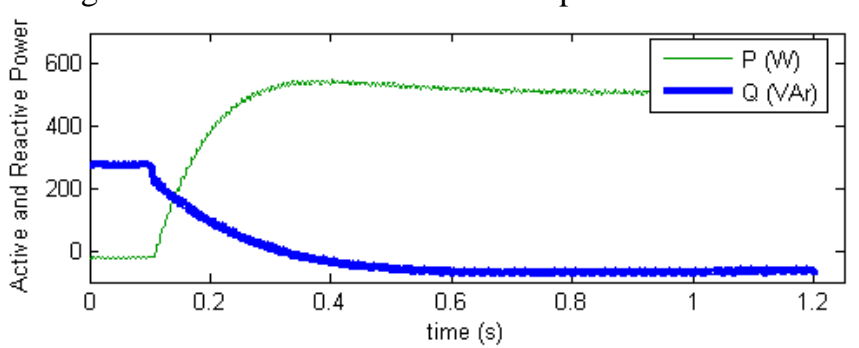

Fig. 16. Active and reactive powers $\left(K_{D}=1 e-3\right)$

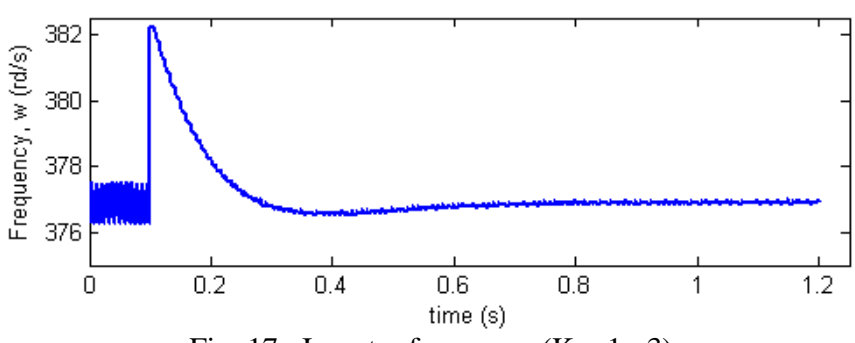

Fig. 17. Inverter frequency $\left(K_{D}=1 e-3\right)$

Figure 17 shows the inverter frequency during the test. Observing figures 15, 16 and 17, we can see that the system is overdamped

It is important to keep in mind that active power deviation implies a jump in inverter phase. The more power deviation the more jump. This implies in voltage waveform distortion, and $K_{D}$ must be limited. That is, there is a compromise between the performance and acceptable distortion level.

\section{CONCLUSIONS}

This paper has presented a small signal analysis for a single-phase inverter connected to the stiff AC system, which uses an improved power controller. A new feedback loop is proposed to increase the system damping. Simulation results show that the system is well represented by the small signal model.

Several root locus plots as a function of the system parameters can be obtained using the proposed model in order to help designers to define the loop gains for an improved performance of the system.

The controller proposed in this paper can be typically applied to cases where inverters are connected to the grid in order to convert the power provided by conventional energy sources or even alternative ones.

A prototype of the proposed system was implemented and its experimental results agree with the preceding theoretical analysis. Two cases were analyzed, comparing the controller performance with and without the proposed feedback loop. It was evident the improving in the performance with the new feedback loop working.

\section{ACKNOWLEDGMENTS}

The authors would like thanking CAPES, CNPq, FAPEMIG, Escola Técnica Federal de Palmas and Universidade Federal de Uberlândia for financial support.

\section{REFERENCES}

[1] M.C. Chandorkar, D.M. Divan and.R. Adapa, "Control of parallel connected inverters in standalone AC supply systems”, IEEE Transactions on Industry Applications, Vol. 29, Issue 1, Part 1, Jan.-Feb. 1993, pp.136-143

[2] M.C. Chandorkar, Distributed Uninterruptible Power Supply Systems, PhD thesis, University of WisconsinMadison, 1995. 
[3] A. Tuladhar, H. Jin, T. Unger, K. Mauch, "Parallel operation of single phase inverter modules with no control interconnections", Applied Power Electronics Conference and Exposition, 1997, APEC '97 Conference Proceedings, 23-27 Feb. 1997, Vol. 1, pp.94-100.

[4] T. Kawabata. and S. Higashino, "Parallel operation of voltage source inverter”, IEEE Transactions on Industry Applications, 24(2), pp. 281-287, 1998.

[5] E.A.A. Coelho, P.C. Cortizo, P.F.D. Garcia, "Small signal stability for single phase inverter connected to stiff AC system”, Industry Applications Conference, 1999, Conference Record of the IEEE Thirty-Fourth IAS Annual Meeting,3-7 Oct. 1999, Vol. 4, pp.2180-2187.

[6] E.A.A. Coelho, P.C. Cortizo, P.F.D. Garcia, "Smallsignal stability for parallel-connected inverters in standalone AC supply systems”, IEEE Transactions on Industry Applications, Vol. 38, Issue 2, March-April 2002, pp.533-542.

[7] E. P. Paiva, Uma Proposta de Controle de Paralelismo de Inversores com a Rede Elétrica Utilizando-se a Técnica de Realimentação de Fase, Doctorade Thesis, Federal University of Uberlândia, 2006.

[8] J.M. Guerrero, J. Matas, L.G. Vicuña, M. Castilla and J. Miret, "Decentralized Control for Parallel Operation of Distributed Generation Inverters Using Resistive Output Impedance”, IEEE Transactions on Industrial Electronics, Vol. 54, Issue 2, April 2007, pp.994-1004.

[9] K. De Brabandere, B. Bolsens, J. Van den Keybus, A.Woyte, J. Driesen, R. Belmans, "A Voltage and Frequency Droop Control Method for Parallel Inverters", IEEE Transactions on Power Electronics,Vol.22, Issue 4, July 2007, pp.1107-1115

[10] P. S. Kundur, Power System Stability and Control. McGraw-Hill, Inc., 1994

[11] M.J. Ryan, W.E. Brumsickle and R.D. Lorenz, "Control topology for single-phase ups inverters”, IEEE Transactions On Industry Applications, 33(2), pp.493500, 1997.

\section{BIOGRAPHIES}

Élcio Precioso de Paiva was born in Uberlândia-MG, Brazil, in 1967. He received the B. S. degree, the M. S. degree and the Ph.D. degree in Electrical Engineering from Federal University of Uberlândia, Brazil, in 1993, 1995 and 2006, respectively.

Presently he works as a teacher at Escola Técnica Federal de Palmas, Tocantins, Brazil. His research interest areas include PWM inverters, Parallel Inverter Connection and DC-DC Converters

João Batista Vieira Júnior was born in Panamá-Go, Brazil, in 1955. He received the B. S. degree in Electrical Engineering from Federal University of Uberlândia, Brazil, in 1980 and the M. S. and Ph.D. degrees from the Federal University of Santa Catarina, Brazil, in 1984 and 1991, respectively. He began working as teacher in Electrical Engineering Department of Federal University of Uberlândia in 1980.
He is presently Professor of Electrical Engineering at the Federal University of Uberlândia, Brazil. His research interest areas include high-frequency power conversion, modeling and control of converters, power factor correction circuits and new converters topologies.

Dr. Vieira Jr. is member of the SBA and member of the Brazilian Society of Power Electronics (SOBRAEP).

Luiz Carlos de Freitas was born in Monte Alegre-MG, Brazil, in 1952. He received the B. S. degree in Electrical Engineering from Federal University of Uberlândia, Brazil, in 1975 and the M. S. and Ph.D. degrees from the Federal University of Santa Catarina, Brazil, in 1985 and 1992, respectively.

He is presently Professor of Electrical Engineering at the Federal University of Uberlândia, Brazil. His research interest areas include high-frequency power conversion, modeling and control of converters, power factor correction circuits and new converters topologies.

Dr. Freitas is member of the SBA and member of the Brazilian Society of Power Electronics (SOBRAEP).

Valdeir José Farias was born in Araguari-MG, Brazil, in 1947. He received the B. S. degree in Electrical Engineering from Federal University of Uberlândia, Brazil, in 1975 and the M. S. degree in Power Electronics from Federal University of Minas Gerais and Ph.D. degree from Universidade Estadual de Campinas , Brazil, in 1981 and 1989 respectively.

Nowadays he is a titular professor of the Electrical Engineering Faculty of the Federal University of Uberlândia, Brazil. His research interest area is Power Electronics, specially Soft-Switching Converters and Active Power Filters.

Dr. Farias is member of the SBA and member of the Brazilian Society of Power Electronics (SOBRAEP).

Ernane Antônio Alves Coelho was born in Teófilo OtoniMG, Brazil, in 1962. He received the B.S. degree in electrical engineering from the Federal University of Minas Gerais, Belo Horizonte, Brazil, the M.S. degree from the Federal University of Santa Catarina, Florianópolis, Brazil, and the Ph.D. degree from the Federal University of Minas Gerais in 1987, 1989, and 2000, respectively.

$\mathrm{He}$ is currently with the Power Electronics Research Group in Federal University of Uberlândia, Uberlândia, Brazil. His research interests are PWM inverters, powerfactor correction, and digital control by microcontrollers and DSPs.

Dr. Coelho is member of the Brazilian Society of Power Electronics (SOBRAEP). 